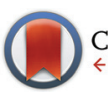

CrossMark $\leftarrow$ click for updates

Cite this: Dalton Trans., 2016, 45 4407

Received 8th September 2015 Accepted 3rd February 2016

DOI: $10.1039 / c 5 d t 03504 j$

www.rsc.org/dalton

\title{
Tuning the flexibility in MOFs by SBU functionalization $\uparrow$
}

\author{
Volodymyr Bon, ${ }^{a}$ Negar Kavoosi, ${ }^{a}$ Irena Senkovska, ${ }^{a}$ Philipp Müller, ${ }^{a}$ Jana Schaber, \\ Dirk Wallacher, ${ }^{c}$ Daniel M. Többens, ${ }^{d}$ Uwe Mueller ${ }^{e}$ and Stefan Kaskel*a
}

\begin{abstract}
A new approach for the fine tuning of flexibility in MOFs, involving functionalization of the secondary building unit, is presented. The "gate pressure" MOF $\left[\mathrm{Zn}_{3}(\mathrm{bpydc})_{2}(\mathrm{HCOO})_{2}\right]$ was used as a model material and SBU functionalization was performed by using monocarboxylic acids such as acetic, benzoic or cinnamic acids instead of formic acid in the synthesis. The resulting materials are isomorphous to $\left[\mathrm{Zn}_{3}(\mathrm{bpydc})_{2}(\mathrm{HCOO})_{2}\right]$ in the "as made" form, but show different structural dynamics during the guest removal. The activated materials have entirely different properties in the nitrogen physisorption experiments clearly showing the tunability of the gate pressure, at which the structural transformation occurs, by using monocarboxylic acids with varying backbone structure in the synthesis. Thus, increasing the number of carbon atoms in the backbone leads to the decreasing gate pressure required to initiate the structural transition. Moreover, in situ adsorption/PXRD data suggest differences in the mechanism of the structural transformations: from "gate opening" in the case of formic acid to "breathing" if benzoic acid is used.
\end{abstract}

\section{Introduction}

Flexible Metal-Organic Frameworks (MOFs) or so called Soft Porous Crystals are a unique class of materials capable to switch between the porous and dense (or less porous) states as a response to external stimuli such as temperature, pressure, electromagnetic irradiation or adsorption of guest molecules. $^{1-3}$ The existence of two different states with different physical and textural properties gives rise to a wide potential application field of such materials. For example, $\mathrm{NH}_{2}$-MIL-53(Al) is able to transform between the narrow and large pore phases and therefore could be used as an optical switch. ${ }^{4}$ Sensor technology is also one of the prospective application fields for switchable MOFs. Thus a $\mathrm{Mg}$ based flexible

\footnotetext{
${ }^{a}$ Department of Inorganic Chemistry, Technische Universität Dresden, Bergstrasse 66, D-01062 Dresden, Germany.E-mail: Stefan.Kaskel@tu-dresden.de

${ }^{b}$ Department of Bioanalytical Chemistry, Technische Universität Dresden, Bergstrasse 66, D-01062 Dresden, Germany

${ }^{c}$ Department of Sample Environments, Helmholtz-Zentrum Berlin für Materialien und Energie, Hahn-Meitner-Platz 1, 14109 Berlin, Germany

${ }^{d}$ Department of Crystallography, Helmholtz-Zentrum Berlin für Materialien und Energie, Hahn-Meitner-Platz 1, 14109 Berlin, Germany

${ }^{e} M X$ Group, Institute for Soft Matter and Functional Materials, Helmholtz-Zentrum Berlin für Materialien und Energie, Albert-Einstein-Str. 15, 12489 Berlin, Germany $\dagger$ Electronic supplementary information (ESI) available: Temperature dependent PXRD measurement for $\mathbf{1}^{\prime}$, TG curves for 1-4 and $\mathbf{2}^{\prime}-\mathbf{4}^{\prime}$, FT-IR spectra for $\mathbf{1}^{\prime}-\mathbf{4}^{\prime}$, and PXRD patterns for $3^{\prime}$ and $4^{\prime}$. CCDC 1422814-1422821. For ESI and crystallographic data in CIF or other electronic format see DOI: 10.1039/c5dt03504j
}

MOF with the composition $\left[\mathrm{Mg}\left(\mathrm{H}_{2} \mathrm{dhtp}\right)\left(\mathrm{H}_{2} \mathrm{O}\right)_{2}\right] \cdot \mathrm{DMAc}$, denoted as AEMOF-1.DMAc (AEMOF-1 - alkaline earth MOF-1; $\mathrm{H}_{4}$ dhtp - 2,5-dihydroxy-terepthalic acid; DMAc - N,N'-dimethylacetamide) was used as a highly efficient luminescent sensor for the real time detection of water traces in various organic solvents. ${ }^{5}$ The flexibility was also successfully used to achieve the separation of $\mathrm{CO}$ and $\mathrm{N}_{2}$, which have very similar physical properties. ${ }^{6}$ The selective trapping of NO molecules in the flexible $\mathrm{Ru}$ - and $\mathrm{Rh}$-based coordination polymers could find its application in biomedicine. ${ }^{7}$

All envisioned applications based on the flexibility require materials with well-defined switching behavior. However, tuning and designing of flexible MOFs with specific switching properties remain very challenging, which limits the application potential of flexible crystalline materials. The most often applied strategies to influence the flexibility in soft MOFs $^{8}$ are: (i) introduction of flexible side chains into the ligand; ${ }^{9}$ (ii) modulation of host-guest interaction strength by linker functionalization; ${ }^{10}$ (iii) incorporation of different metals into the same framework; ${ }^{11}$ (iv) adjustment of the crystal size. ${ }^{12}$

In this contribution, we present a switchability tuning approach based on the systematic substitution of monocarboxylates in the secondary building unit (SBU) of a "gate pressure" MOF $\left[\mathrm{Zn}_{3}(\text { bpydc })_{2}(\mathrm{HCOO})_{2}\right]$ (bpydc - 2,2'-bipyridine-5,5'-dicarboxylate), also known as JLU-Liu4 (JLU - JiLin University). ${ }^{13}$ It contains two formic acid anions directly coordinated to the metal cluster. The solvent assisted exchange of the 
monocarboxylic ligand was already demonstrated for rigid $\mathrm{Zr}$ based MOFs. ${ }^{14}$ We could show that utilizing monocarboxylic acids with different backbones in the synthesis (for instance acetic, benzoic, or cinnamic acid) results in the formation of isomorphous frameworks, showing completely different adsorption behavior. Crystal structures of the large pore and narrow pore phases as well as adsorption behavior of the materials bearing different monocarboxylic ligands were studied to enlighten the structural transformations in quest.

\section{Experimental}

\section{Materials}

All chemicals were purchased from commercial sources and used without further purification. N,N-Dimethylformamide (DMF) (anhydrous 99.8\%), trans-cinnamic acid (97\%), acetonitrile (99.8\%), and 5,5'-dimethyl-2,2'-dipyridine (98\%, dmpby) were purchased from Sigma Aldrich. 2,2'-Bipyridyl-5,5'-dicarboxylic acid $\left(\mathrm{H}_{2}\right.$ bpydc) was synthesised according to the reported procedure ${ }^{15}$ (for more details see the ESI†). Benzoic acid $(99.5 \%)$ and formic acid (99\%) were purchased from Grüssing $\mathrm{GmbH}, \mathrm{Zn}\left(\mathrm{NO}_{3}\right)_{2} \cdot 4 \mathrm{H}_{2} \mathrm{O}$ from Merck, acetic acid (100\%) from Roth and Company, heptane (99\%) and dichloromethane 99.99\% from Fisher, anhydrous toluene from VWR, and 1-propanol 99.5\% from TCI.

\section{Synthesis}

[ $\mathrm{Zn}_{3}(\text { bpydc })_{2}(\mathrm{HCOO})_{2}$ ] JLU-Liu4 (1). JLU-Liu4 (1) was synthesized using a slightly modified procedure. $\mathrm{Zn}\left(\mathrm{NO}_{3}\right)_{2} \cdot 4 \mathrm{H}_{2} \mathrm{O}$ (52.2 $\mathrm{mg}, 0.2 \mathrm{mmol}), \mathrm{H}_{2}$ bypdc $(20 \mathrm{mg}, 0.082 \mathrm{mmol})$ and formic acid (1 mL, $26.5 \mathrm{mmol}$ ) were mixed with $6.5 \mathrm{~mL}$ DMF and transferred to the Pyrex@ tubes. The mixture was heated for $24 \mathrm{~h}$ at $120^{\circ} \mathrm{C}$. The resulting white octahedral crystals were filtered off and washed 3 times with DMF. Filtration was performed under argon flow. After that, the solvent was exchanged with ethanol over a period of 3 days. At the end, the sample was activated for 5 hours at $70{ }^{\circ} \mathrm{C}$ under dynamic vacuum. Yield: $32.2 \mathrm{mg}$ (63\%). After activation, all samples were handled under an argon atmosphere. The PXRD patterns obtained for the "as made" and activated samples confirmed the phase purity.

$\left[\mathrm{Zn}_{3}(\text { bpydc })_{2}\left(\mathrm{CH}_{3} \mathrm{COO}\right)_{2}\right]$ (2). A mixture of $\mathrm{Zn}\left(\mathrm{NO}_{3}\right)_{2} \cdot 4 \mathrm{H}_{2} \mathrm{O}$ (52.2 $\mathrm{mg}, 0.2 \mathrm{mmol}$ ), $\mathrm{H}_{2}$ bypdc $(20 \mathrm{mg}, 0.082 \mathrm{mmol}$ ), and acetic acid $(1 \mathrm{~mL}, 17.5 \mathrm{mmol})$ with $6.5 \mathrm{~mL}$ DMF was added to Pyrex@ tubes and heated $24 \mathrm{~h}$ at $120^{\circ} \mathrm{C}$. Then crystals were collected and washed several times first with DMF and then with ethanol. Subsequently, they were immersed in dry ethanol for 3 days. The crystals were filtered off under argon flow and evacuated for $12 \mathrm{~h}$ at $70^{\circ} \mathrm{C}$. Yield: $17.26 \mathrm{mg}(52.5 \%)$.

Elemental analysis (wt\%): calc. C 42.89, N 6.98, H 2.74; found C 41.13, N 7.26, H 1.03.

$\left[\mathrm{Zn}_{3}(\text { bpydc })_{2}\left(\mathrm{C}_{6} \mathrm{H}_{5} \mathbf{C O O}\right)_{2}\right] \quad$ (3). $\mathrm{Zn}\left(\mathrm{NO}_{3}\right)_{2} \cdot 4 \mathrm{H}_{2} \mathrm{O} \quad(52.2 \mathrm{mg}$, $0.2 \mathrm{mmol}), \mathrm{H}_{2}$ bypdc $(20 \mathrm{mg}, 0.082 \mathrm{mmol}$ ), and benzoic acid $(1.4 \mathrm{~g}, 11.5 \mathrm{mmol})$ were dissolved in $6.5 \mathrm{~mL}$ DMF. The mixture was placed into the Pyrex@ tubes and heated at $120{ }^{\circ} \mathrm{C}$ for
$48 \mathrm{~h}$. Washing and activation procedures were the same as described for compound 2. Yield: $16 \mathrm{mg}$ (42.65\%).

Elemental analysis (wt\%): calc. C 49.23, N 6.04, H 2.8; found C 48.18, N 6.16, H 1.27.

[ $\left.\mathrm{Zn}_{3}(\text { bpydc })_{2}\left(\mathrm{C}_{6} \mathbf{H}_{5} \mathbf{C H C H C O O}\right)_{2}\right]$ (4). A mixture of $\mathrm{Zn}\left(\mathrm{NO}_{3}\right)_{2}$. $4 \mathrm{H}_{2} \mathrm{O}(52.2 \mathrm{mg}, 0.2 \mathrm{mmol}), \mathrm{H}_{2}$ bypdc $(20 \mathrm{mg}, 0.082 \mathrm{mmol})$, and cinnamic acid $(1.25 \mathrm{~g}, 8.4 \mathrm{mmol})$ with $6.5 \mathrm{~mL}$ DMF was placed into the Pyrex@ tubes and heated at $80{ }^{\circ} \mathrm{C}$ for $72 \mathrm{~h}$. Washing and activation procedures were the same as described for compound 2. Yield: $21 \mathrm{mg}$ (53\%).

Elemental analysis (wt\%): calc. C 51.52, N 5.72, H 3.06; found C 49.77, N 5.87, H 1.96 .

\section{Single crystal X-ray diffraction}

The crystal structure of compounds 1-4 were determined by single crystal X-ray diffraction. All single crystals were prepared in glass capillaries with some amount of solvent. The capillaries were sealed with melted wax. The datasets were collected at the BESSY MX BL14.2 beamline of Helmholtz-Zentrum Berlin für Materialien und Energie (HZB). ${ }^{16}$ All diffraction experiments were performed at room temperature using radiation with an energy of $14 \mathrm{keV}(\lambda=0.88561 \AA)$. The $\phi$-scans with an oscillation range of $1^{\circ}$ were used for data collection. The datasets were processed using CCP4 software. ${ }^{17}$ The crystal structures were solved by direct methods and refined by full matrix least-squares on $F^{2}$ using the SHELXTL program package. ${ }^{18}$ All non-hydrogen atoms were refined in anisotropic approximation. Hydrogen atoms were refined in the geometrically calculated positions using the "riding model" with $U_{\text {iso }}(\mathrm{H})=1.2 U_{\text {iso }}(\mathrm{C})$ for sp, $\mathrm{sp}^{2}$ hybridized carbon atoms and with $U_{\text {iso }}(\mathrm{H})=1.5 U_{\text {iso }}(\mathrm{C})$ for $\mathrm{sp}^{3}$ hybridized carbon atoms. The atoms of the phenyl rings of the benzoate (compound 3) and cinnamate (compound 4) anions are disordered and were treated using the AFIX 66 instruction. In the case of compound 4, SIMU and DELU instructions have been used to restrain the thermal parameters of disordered fragments. Because of the high symmetry of the crystal system it was not possible to localize the lattice solvent molecules in the pores. Therefore, the SQUEEZE procedure was used to correct reflection intensities, corresponding to disordered solvent molecules. ${ }^{19}$ CCDC $1422814,1422816,1422818$ and 1422820 contain the supplementary crystallographic data for compounds $1,2,3$, and $\mathbf{4}$, respectively. The extended crystallographic data for the structures 1-4 are given in Table S1 of the ESI. $\dagger$

Crystal data for $\left[\mathrm{Zn}_{3}(\text { bpydc })_{2}(\mathrm{HCOO})_{2}\right]$ (1). $\mathrm{C}_{26} \mathrm{H}_{14} \mathrm{~N}_{4} \mathrm{O}_{12} \mathrm{Zn}_{3}$, $M=770.52 \mathrm{~g} \mathrm{~mol}^{-1}$, tetragonal, $P 4_{3} 2_{1} 2$ (no. 96), $a=15.320(2)$ $\AA$, $c=23.240(5) \AA, V=5454.5(18) \AA^{3}, Z=4, \rho_{\text {calc }}=0.938 \mathrm{~g} \mathrm{~cm}^{-3}$, $\lambda=0.88561 \AA, T=298 \mathrm{~K}, \theta_{\max }=32.1^{\circ}$, reflections collected $/$ unique $12822 / 5847, R_{\text {int }}=0.0194, R_{1}=0.0287, \mathrm{w} R_{2}=0.0852$, $S=1.089$, largest diff. peak 0.569 e $\AA^{-3}$ and hole -0.543 e $\AA^{-3}$.

Crystal data for $\left[\mathrm{Zn}_{3}(\text { bpydc })_{2}\left(\mathrm{CH}_{3} \mathbf{C O O}\right)_{2}\right]$ (2). $\mathrm{C}_{28} \mathrm{H}_{18} \mathrm{~N}_{4} \mathrm{O}_{12} \mathrm{Zn}_{3}$, $M=798.57 \mathrm{~g} \mathrm{~mol}^{-1}$, tetragonal, $P 4_{3} 2_{1} 2$ (no. 96), $a=15.300$ (2) $\AA ̊ ㇒=23.280(5) \AA, V=5449.6(18) \AA^{3}, Z=4, \rho_{\text {calc }}=0.973 \mathrm{~g} \mathrm{~cm}^{-3}$, $\lambda=0.88561 \AA, T=298 \mathrm{~K}, \theta_{\max }=32.1^{\circ}$, reflections collected/ unique $19800 / 6337, R_{\text {int }}=0.0275, R_{1}=0.0313, \mathrm{w} R_{2}=0.0960$, $S=1.099$, largest diff. peak 0.629 e $\AA^{-3}$ and hole -0.532 e $\AA^{-3}$. 
Crystal data for $\left[\mathrm{Zn}_{3}(\text { bpydc })_{2}\left(\mathrm{C}_{6} \mathbf{H}_{5} \mathrm{COO}\right)_{2}\right]$

(3). $\mathrm{C}_{38} \mathrm{H}_{22} \mathrm{~N}_{4} \mathrm{O}_{12} \mathrm{Zn}_{3}, M=922.70 \mathrm{~g} \mathrm{~mol}^{-1}$, tetragonal, $P 4_{3} 2_{1} 2$ (no. 96), $a=15.160(2) \AA, c=23.030(5) \AA, V=5292.9(18) \AA^{3}, Z=4$, $\rho_{\text {calc }}=1.158 \mathrm{~g} \mathrm{~cm}^{-3}, \lambda=0.88561 \AA, T=298 \mathrm{~K}, \theta_{\max }=32.1^{\circ}$, reflections collected/unique $40507 / 6196, R_{\text {int }}=0.0556, R_{1}=$ $0.0515, \mathrm{w} R_{2}=0.1546, S=1.079$, largest diff. peak $0.656 \mathrm{e}^{-3}$ and hole -0.764 e $\AA^{-3}$.

Crystal data for $\left[\mathrm{Zn}_{3}(\text { bpydc })_{2}\left(\mathrm{C}_{6} \mathrm{H}_{5} \mathrm{CH}=\mathrm{CHCOO}\right)_{2}\right]$ (4). $\mathrm{C}_{42} \mathrm{H}_{26} \mathrm{~N}_{4} \mathrm{O}_{12} \mathrm{Zn}_{3}, M=974.78 \mathrm{~g} \mathrm{~mol}^{-1}$, tetragonal, $P 4_{3} 2_{1} 2$ (no. 96), $a=15.270(2) \AA, c=23.050(5) \AA, V=5374.6(18) \AA^{3}, Z=4$, $\rho_{\text {calc }}=1.205 \mathrm{~g} \mathrm{~cm}^{-3}, \lambda=0.88561 \AA, T=298 \mathrm{~K}, \theta_{\text {max }}=32.1^{\circ}$, reflections collected/unique $20740 / 6207, R_{\text {int }}=0.0556, R_{1}=$ $0.0377, \mathrm{w} R_{2}=0.1195, S=1.123$, largest diff. peak $0.500{\mathrm{e} \AA^{-3}}^{-3}$

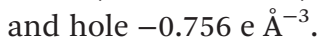

\section{Crystal structures of $\mathbf{1}^{\prime}-\mathbf{4}^{\prime}$ determined from PXRD}

The crystal structures for narrow pore phases were solved from the PXRD patterns that were recorded at room temperature on the evacuated samples. Data for $\mathbf{1}^{\prime}, \mathbf{3}^{\prime}$, and $\mathbf{4}^{\prime}$ were collected at the BESSY KMC-2 beamline of HZB in transmission geometry using 2 scans in the range of 5 to $50^{\circ}$. Data for $2^{\prime}$ were collected on STOE Stadi P. The patterns were indexed using the X-Cell program implemented in Material Studio 5.0 software. $^{20}$ The most intensive reflections in the $2 \theta$ range between 2 and $20^{\circ}$ were used for indexing. The $C 222_{1}$ space group was chosen for $\mathbf{1}^{\prime}, \mathbf{2}^{\prime}$, and $\mathbf{4}^{\prime}$ considering the group-subgroup relationships and extinction rules. The starting models for the crystal structure refinement were derived from the "as made" 1, 2, and 4 structures, which were converted into the corresponding space group. After adapting the unit cell parameters to those obtained during indexing, the structural models were optimized using a geometry optimization tool with implementation of a universal force field. Due to the low data/parameter ratio, the rigid-body Rietveld refinement with energy options was used to refine the structures.

The crystallographically independent $\mathrm{Zn}$ atoms, carboxylate groups, and phenyl rings were treated as rigid bodies.

In the case of compound 2 ', the minor impurity of open phase 2 is present after activation. Therefore, reflections at $7.0^{\circ}$ and $11.6^{\circ} 2 \theta$, which belong to the open phase 2 (Fig. 3), were excluded from the Rietveld refinement.

The final Rietveld plots are given in Fig. 1. CCDC 1422815, 1422817, 1422819 and 1422821 contain the supplementary crystallographic data for compounds $\mathbf{1}^{\prime}, \mathbf{2}^{\prime}, \mathbf{3}^{\prime}$, and $\mathbf{4}^{\prime}$, respectively.

Refinement data for $\mathbf{Z n}_{3}(\text { bpydc })_{2}(\mathrm{HCOO})_{2} \quad\left(\mathbf{1}^{\prime}\right)$. $\mathrm{C}_{26} \mathrm{H}_{14} \mathrm{~N}_{4} \mathrm{O}_{12} \mathrm{Zn}_{3}, F_{\mathrm{w}}=770.58$, orthorhombic, $C 222_{1}$ (no. 20), $a=27.821(1) \AA, b=10.184(1) \AA, c=21.626(1) \AA, V=6127.4(3)$ $\AA^{3}, Z=8,12$ refined motion groups, 56 refined DOF, $R_{\mathrm{wp}}=$ $15.68 \%, R_{\mathrm{p}}=12.20 \%$.

Refinement data for $\mathbf{Z n}_{3}(\text { bpydc })_{2}\left(\mathbf{C H}_{3} \mathrm{COO}\right)_{2} \quad\left(2^{\prime}\right)$. $\mathrm{C}_{28} \mathrm{H}_{18} \mathrm{~N}_{4} \mathrm{O}_{12} \mathrm{Zn}_{3}, F_{\mathrm{w}}=798.63$, orthorhombic, $C 222_{1}$ (no. 20), $a=27.715(1) \AA, b=10.575(1) \AA, c=21.691(1) \AA, V=6245.4(3)$ $\AA^{3}, Z=8,14$ refined motion groups, 68 refined DOF, excluded regions $6.60-7.30,11.50-11.77, R_{\mathrm{wp}}=7.60 \%, R_{\mathrm{p}}=5.83 \%$.
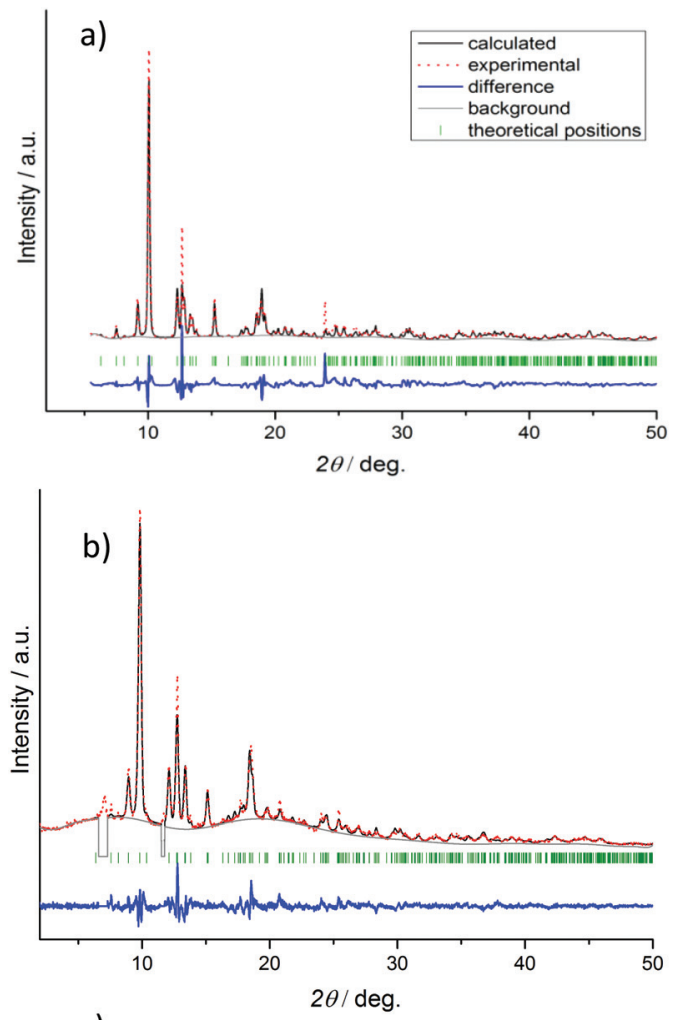

c)
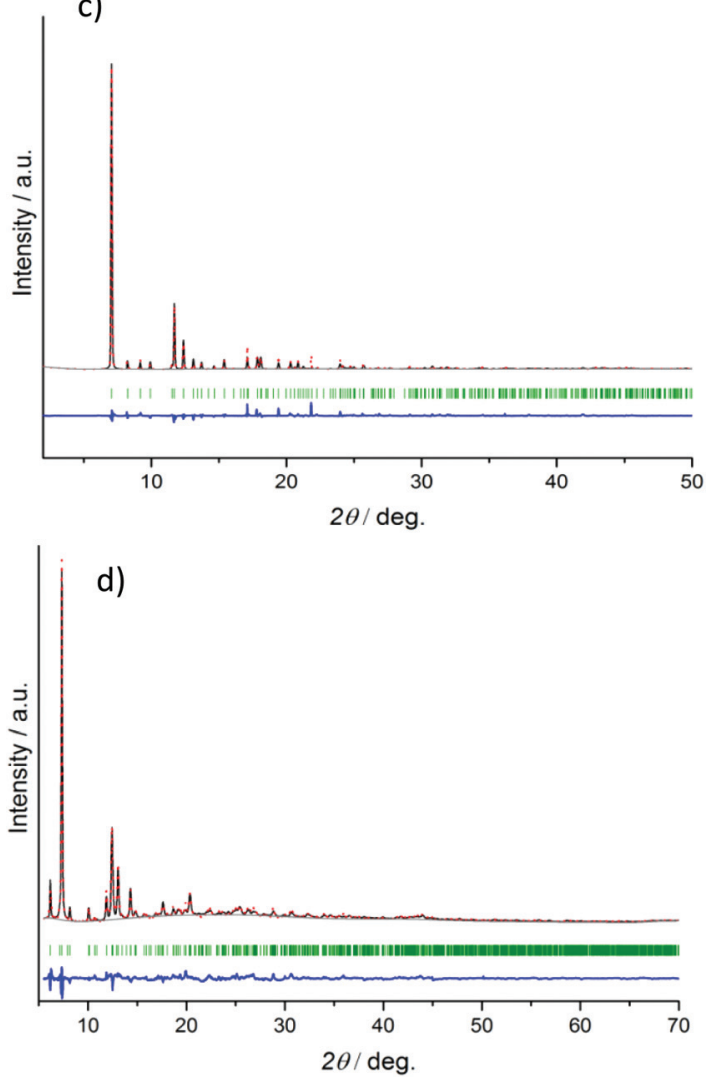

Fig. 1 Rietveld plots for compounds 1' (a), 2' (b), 3' (c), and 4' (d). 
Refinement data for $\mathrm{Zn}_{3}(\text { bpydc })_{2}\left(\mathrm{C}_{6} \mathrm{H}_{5} \mathrm{COO}\right)_{2} \quad\left(3^{\prime}\right)$. $\mathrm{C}_{38} \mathrm{H}_{22} \mathrm{~N}_{4} \mathrm{O}_{12} \mathrm{Zn}_{3}, F_{\mathrm{W}}=922.77$, tetragonal, $P 4_{3} 2_{1} 2$ (no. 96), $a=$ 15.019(1) А, $c=21.905(2) \AA, V=4941.4(3) \AA^{3}, Z=4,6$ refined motion groups, 28 refined DOF, $R_{\mathrm{wp}}=17.99 \%, R_{\mathrm{p}}=12.10 \%$.

Refinement data for $\mathbf{Z n}_{3}(\text { bpydc })_{2}\left(\mathrm{C}_{6} \mathrm{H}_{5} \mathrm{CHCHCOO}\right)_{2} \quad\left(4^{\prime}\right)$. $\mathrm{C}_{42} \mathrm{H}_{26} \mathrm{~N}_{4} \mathrm{O}_{12} \mathrm{Zn}_{3}, F_{\mathrm{w}}=974.84$, orthorhombic, $C 222_{1}$ (no. 20), $a=17.313$ (1) ̊, $b=24.594(1) \AA, c=22.139(2) \AA, V=9426.6(3)$ $\AA^{3}, Z=8$, 18 refined motion groups, 92 refined DOF, $R_{\mathrm{wp}}=$ $11.65 \%, R_{\mathrm{p}}=8.98 \%$.

\section{In situ monitoring of nitrogen adsorption (77 K) by powder X-ray diffraction}

Concerted adsorption of $\mathrm{N}_{2}$ and X-ray powder diffraction experiments on compounds $\mathbf{3}$ and $\mathbf{4}$ were performed at the KMC-2 beamline of HZB using specially designed instrumentation. ${ }^{21}$ All adsorption experiments were performed at $77 \mathrm{~K}$ in the relative pressure range between $10^{-3}$ and $1\left(p_{0}=101.3 \mathrm{kPa}\right)$. All diffraction measurements were performed in the $2 \theta$ range from 2 to $50^{\circ}$ using monochromatic synchrotron radiation (8048 $\mathrm{eV} ; \lambda=1.5406 \AA$ ). The diffraction images from the VÅNTEC-2000 $2 \mathrm{D}$ detector were integrated using Datasqueeze 2.2.9 software. $^{22}$ Hexagonal boron nitride was used as an external standard.

\section{Physical measurements}

Thermogravimetric analyses were carried out under air using STA 409 PC from the NETZSCH Company. Mass analysis was performed using Aëolos QMS 403 from the NETZSCH Company. The heating rate was set to $5 \mathrm{~K} \mathrm{~min}^{-1}$. FT-IR spectra were measured on a VERTEX-70 spectrophotometer (Bruker) using the DRIFT technique. Nitrogen adsorption measurements up to $100 \mathrm{kPa}$ at $77 \mathrm{~K}$ were performed on approximately $35 \mathrm{mg}$ of sample using BELSORP-max apparatus. The nitrogen with the purity of $99.999 \%$ was used for the experiments. Powder X-ray diffraction patterns were obtained on a STADI P (Stoe) diffractometer at RT using monochromatic $\mathrm{Cu}-\mathrm{K} \alpha_{1}$ radiation $(\lambda=1.5406 \AA$ ) (step size: 0.05 , exposure time: 23 s per point). All measurements were performed in transmission geometry. The samples were prepared in the Ar-filled glovebox. Temperature dependent PXRD measurements were performed on an X'Pert Pro diffractometer (PANalytical) in reflection geometry using $\theta / 2 \theta$ scans and a MRI (Material Research Instruments) sample stage. The PXRD patterns were obtained under dynamic vacuum every $25{ }^{\circ} \mathrm{C}$ in the temperature range between 25 and $450{ }^{\circ} \mathrm{C}$. The heating rate was set to $3 \mathrm{~K} \mathrm{~min}^{-1}$.

\section{Results and discussion}

JLU-Liu4 developed by Liu and co-workers consists of trinuclear $\mathrm{Zn}$ (II) units coordinated by four carboxylic groups, two 2,2'-bipyridine units, and two formate anions. The structure comprises of a 3D framework (ant topology) and displays channels $4.9 \times 5.1 \AA$ in dimensions. ${ }^{13}$ The $3 \mathrm{D}$ framework of JLU-Liu4 undergoes structural transformation upon removal of guest molecules from the pores to give a MOF with gate opening behavior. This is indicated by shifting and intensity

changing of the peaks in the PXRD pattern. However, the structure of the desolvated compound has not yet been reported.

To study the influence of the monocarboxylic ligand nature on the structure formation of JLU-Liu4 (1), acetic (HAc), benzoic ( $\mathrm{HBz})$, or cinnamic ( $\mathrm{HCn}$ ) acid was used in the synthesis instead of the originally reported formic acid.

In all cases crystalline products with the composition $\mathrm{Zn}_{3}(\text { bpydc })_{2}(\mathrm{Ac})_{2}(2), \mathrm{Zn}_{3}(\text { bpydc })_{2}(\mathrm{Bz})_{2}$ (3), and $\mathrm{Zn}_{3}(\text { bpydc })_{2}(\mathrm{Cn})_{2}$ (4) could be obtained. Since all new materials could be obtained as crystals suitable for single crystal X-ray analysis, the crystal structures of all new materials were determined. All compounds crystallize in the same space group $P_{3} 2_{1} 2$, and are isostructural, possessing similar frameworks with the ant topology (Fig. 2a). As expected, the main difference in the structures is the monocarboxylic ligand being included (Fig. 2b-e). According to the PLATON report, the solvent accessible void in the as made crystal structures changes from $59.4 \%$ in $\mathbf{1}$ to $32.6 \%$ in $\mathbf{4}$ (Table 1). The volume of monocarboxylic anions (calculated as the Connolly solvent excluded volume using ChemDraw software) and the change in the solvent accessible void volume of the unit cell during activation are given in Scheme 1.

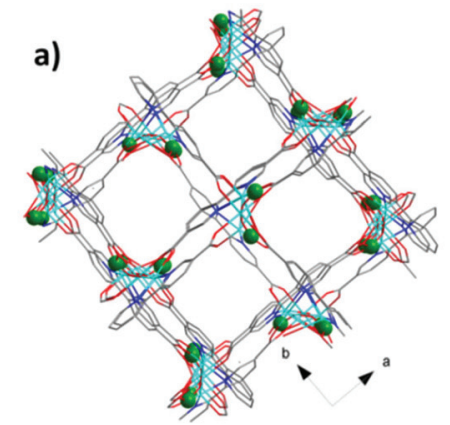

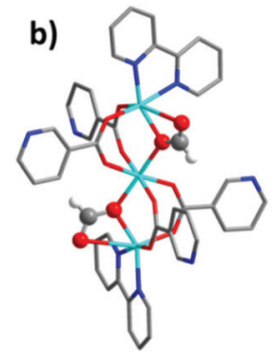
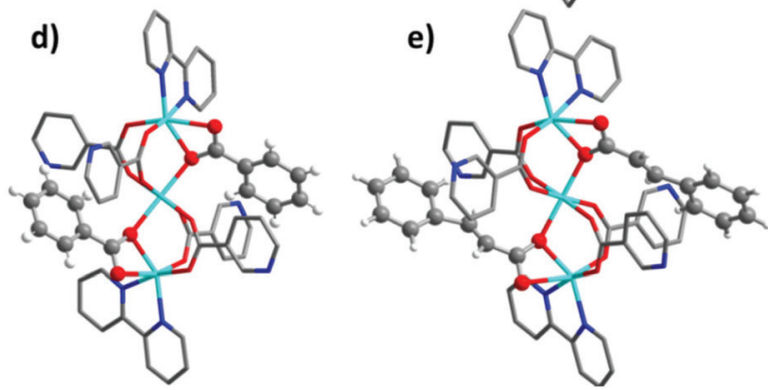

Fig. 2 (a) View of the structure of the JLU-LIU4 framework along the $c$ axis (green spheres represent monocarboxylate anions). (b-e) Structure of SBUs in compounds 1-4. Colour code: turquoise - Zn atoms, grey carbon atoms, red - oxygen atoms, and blue - nitrogen atoms. 


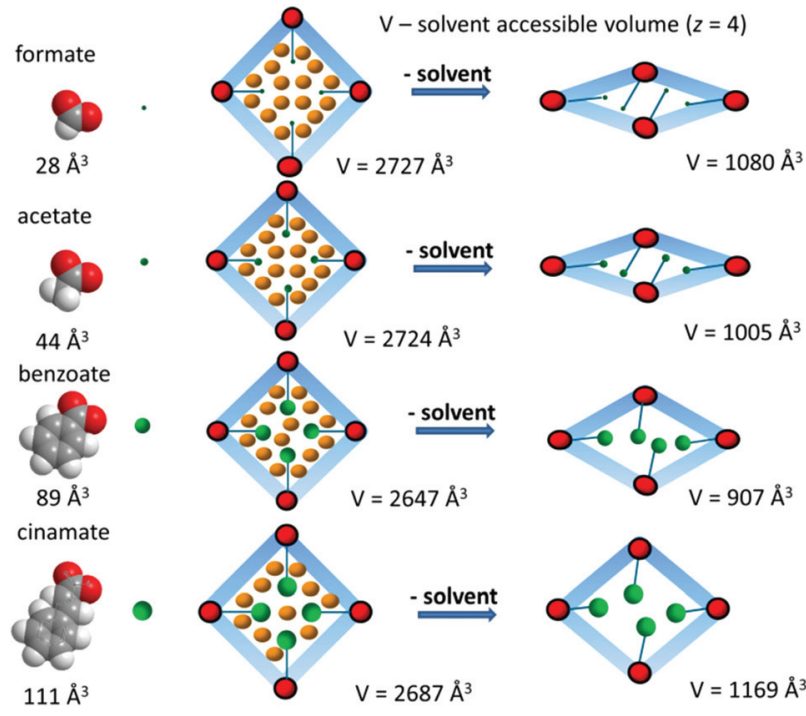

Scheme 1 Schematic representation of the monocarboxylic ligand influence on the activation of the LiU-4 series. The volume of monocarboxylic anions was calculated as the Connolly solvent excluded volume using ChemDraw software. The specified volume represents the solvent accessible volume of the unit cell for $Z=4$.

Table 1 Calculated textural properties of the investigated compounds

\begin{tabular}{llll}
\hline Compound & $\begin{array}{l}\text { Solvent accessible } \\
\text { void volume } \\
\text { of unit cell/\% }\end{array}$ & $\begin{array}{l}\text { Calculated } \\
\text { pore volume } \\
\left(V_{\mathrm{p}}\right) / \mathrm{cm}^{3} \mathrm{~g}^{-1}\end{array}$ & $\begin{array}{l}\text { Calculated } \\
\text { geometrical } \\
\text { surface area } / \mathrm{m}^{2} \mathrm{~g}^{-1}\end{array}$ \\
\hline $\mathbf{1}$ & 59.4 & 0.70 & 2425 \\
$\mathbf{1}^{\prime}$ & 17.6 & 0.09 & 76 \\
$\mathbf{2}$ & 55.7 & 0.63 & 2142 \\
$\mathbf{2}^{\prime}$ & 15.8 & 0.09 & 66 \\
$\mathbf{3}$ & 40.5 & 0.36 & 1047 \\
$\mathbf{3}^{\prime}$ & 36.7 & 0.30 & 690 \\
$\mathbf{4}$ & 32.6 & 0.30 & 747 \\
$\mathbf{4}^{\prime}$ & 24.8 & 0.17 & 188
\end{tabular}

After removal of the solvent molecules, crystallographic transformation takes place in all compounds, according to the changes in the PXRD patterns (Fig. 3). The patterns of all activated compounds (further referred to as $\mathbf{1}^{\prime}, \mathbf{2}^{\prime}, \mathbf{3}^{\prime}$, and $\mathbf{4}^{\prime}$, respectively) were successfully indexed and the crystal structures were solved using molecular simulations combined with the Rietveld refinement.

Activated phases $\mathbf{1}^{\prime}$ and $\mathbf{2}^{\prime}$ have very similar structures: both crystallize in the $C 222_{1}$ space group with similar unit cell parameters (due to this similarity, only the structure of $\mathbf{1}^{\prime}$ is described in detail below). The $C 222_{1}$ space group is a sub-group of the $\mathrm{P}_{3} 2_{1} 2$ (the space group of the parent compounds $\mathbf{1}$ and 2).

Due to the rigidity of the linker, the main contribution to the structural transformation comes from the cluster distortion. The reduction of the symmetry creates two independent SBUs (SBU 1 and SBU 2) in $\mathbf{1}^{\prime}$ showing differences in distortion with respect to the linearity of the $\mathrm{Zn}_{3}$ array and coordination environment of the ligand molecules. In SBU 1, the angle between three $\mathrm{Zn}$ atoms decreases from $178.65(1)^{\circ}$ in 1 to

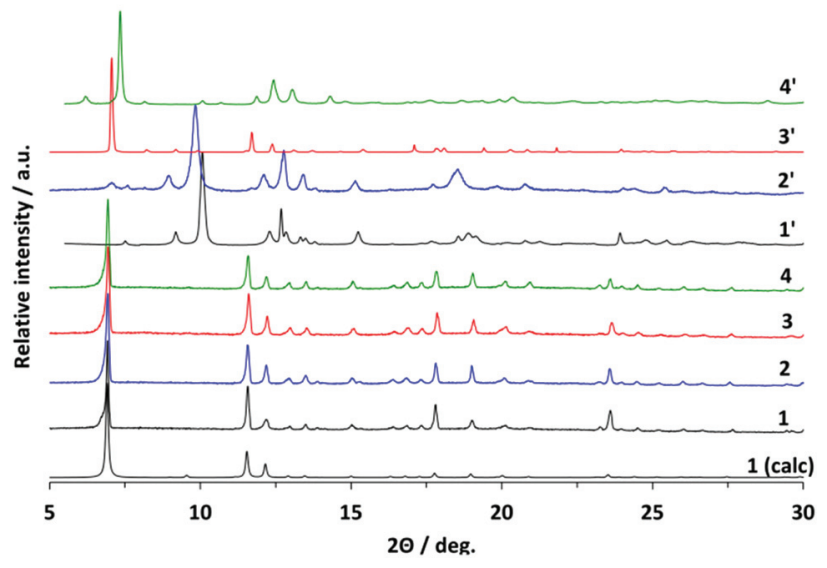

Fig. 3 PXRD patterns for compounds 1-4 and 1'-4'. a)
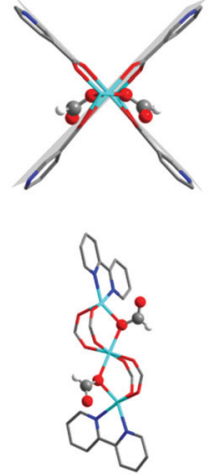

c)

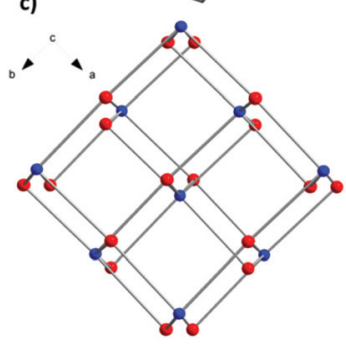

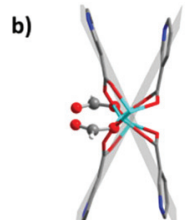

SBU 1

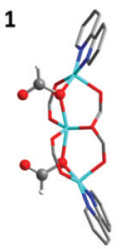

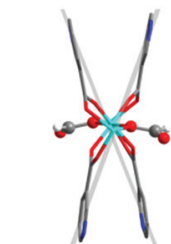

SBU 2

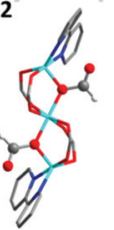

d)

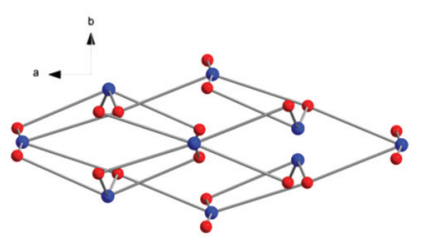

Fig. 4 (a) SBU 1 of 1; (b) SBU 1 and SBU 2 of 1'; (c) crystal structure of 1; (d) crystal structure of 1'. (Colour code in (c) and (d): blue spheres - SBU units, and red spheres - bpydc ${ }^{2-}$ linkers).

$160.48(1)^{\circ}$ in $1^{\prime}$. The angle between the planes involving two 2,2'-bipyridine moieties coordinated to the same cluster changes from $80.31(5)^{\circ}$ in $\mathbf{1}$ to $57.53(5)^{\circ}$ in $\mathbf{1}^{\prime}$ (Fig. $4 \mathrm{a}$ and b). A significant contribution to the structural contraction originates from the bending of carboxylate hinges (dihedral angles between the plane of the carboxylate group and the $\mathrm{O}-\mathrm{Zn}-\mathrm{Zn}-\mathrm{O}$ plane). These change from $5.75(3)^{\circ}$ and $6.07(3)^{\circ}$ in 1 to $19.42(3)^{\circ}$ and $20.63(3)^{\circ}$ in $\mathbf{1}^{\prime}$. This is also often the source of flexibility and structural transitions in other switchable MOFs. ${ }^{23,24}$ The $\mathrm{Zn}$ atoms in SBU 2 are arranged in a nearly linear fashion with a $\mathrm{Zn} \cdots \mathrm{Zn} \cdots \mathrm{Zn}$ angle of $176.67(1)^{\circ}$. The formate anions, which are coordinated on the opposite sides of SBU in $\mathbf{1}$ (Fig. 4a and b) change the position in SBU 1 of $\mathbf{1}^{\prime}$ and move to the same side of the cluster (Fig. $4 \mathrm{~b}$ ). 
On the framework level, the structural contraction in 1 occurs along the [110] direction (Fig. 4c), corresponding to the [010] direction in $\mathbf{1}^{\prime}$ (Fig. 4d).

The textural properties of $\mathbf{1}^{\prime}$ calculated using Poreblazer 3.0.2 software $^{25}$ show that the compound has nearly no accessible pore volume $\left(0.09 \mathrm{~cm}^{3} \mathrm{~g}^{-1}\right)$ as well as a very small pore limiting diameter of $2.11 \AA$ A. This completely supports the experimental results, since $\mathbf{1}^{\prime}$ shows no uptake of nitrogen up to reaching the "gate opening pressure" of 0.47 .

The crystal structure of compound $3^{\prime}$ was refined in the same space group as the structure of 3 (Fig. 1) with different lattice cell constants. Obviously, compound 3 cannot undergo complete transformation because of the bulky phenyl rings of the benzoate. They hinder the cluster transformation as it occurs in 1. Namely, two coordinated benzoate anions, located on the opposite sides of the $\mathrm{Zn}$ cluster in 3 cannot regroup in the same way as in $\mathbf{1}$, and are located on the same side of the SBU plane, because of the small aperture between the ligand molecules, coordinated to the cluster.

The comparison of the calculated pore volumes for 3 and $3^{\prime}$ shows only minor changes from $0.36 \mathrm{~cm}^{3} \mathrm{~g}^{-1}$ to $0.30 \mathrm{~cm}^{3} \mathrm{~g}^{-1}$.

The thermal stability of the investigated materials was studied by temperature dependent PXRD and thermogravimetric (TG) analysis (Fig. S2-S8 ESI $\dagger$ ). Investigation of $\mathbf{1}^{\prime}$ by thermo-XRD under an argon atmosphere confirms the retention of crystallinity up to $300{ }^{\circ} \mathrm{C}$ (see ESI, Fig. S1†) confirming the TG data reported earlier. ${ }^{13}$ According to the TG analysis data, materials $\mathbf{2}^{\prime}, \mathbf{3}^{\prime}$, and $\mathbf{4}^{\prime}$ are stable up to $300{ }^{\circ} \mathrm{C}$, $330{ }^{\circ} \mathrm{C}$, and $320^{\circ} \mathrm{C}$, respectively (see ESI, Fig. S6-S8 $\dagger$ ). Therefore, the samples were activated at $150{ }^{\circ} \mathrm{C}$ in a vacuum prior to the adsorption experiments.

Compound 1' shows classical gate pressure behaviour during physisorption of nitrogen at $77 \mathrm{~K}$, with almost no uptake up to $p / p_{0}=0.47$. The total pore volume calculated at $p / p_{0}=0.95$ amounts to $0.55 \mathrm{~cm}^{3} \mathrm{~g}^{-1}$ which is slightly lower than the theoretical value (Table 1). As expected, the nitrogen adsorption isotherm of $2^{\prime}$ shows a slightly different trend, reaching the plateau after adsorbing nearly $25 \mathrm{~cm}^{3} \mathrm{~g}^{-1}$ nitrogen at very low relative pressures. After reaching $p / p_{0}=0.3$, a very steep increase in uptake takes place. The isotherm reaches a second plateau at $p / p_{0}=0.95$. The adsorbed amount in saturation is $295 \mathrm{~cm}^{3} \mathrm{~g}^{-1}$ that corresponds to the pore volume of $0.456 \mathrm{~cm}^{3} \mathrm{~g}^{-1}$. Materials $3^{\prime}$ and $4^{\prime}$ show completely different behaviour during the adsorption of the nitrogen at $77 \mathrm{~K}$ (Fig. 5). Thus, compound 3' adsorbs nearly $100 \mathrm{~cm}^{3} \mathrm{~g}^{-1}$ of nitrogen already at $p / p_{0}=10^{-4}$ confirming the incompleteness of the crystal structure closing (narrow pore state) of $3^{\prime}$ discussed above. The second step in the isotherm, most likely connected to the structural transformation, occurs in the relative pressure range between 0.03 and 0.07. After that the course of the isotherm is characterized by the continuous increase of the uptake reaching $227 \mathrm{~cm}^{3} \mathrm{~g}^{-1}$ at $p / p_{0}=0.97$.

Implementation of the larger cinnamate anion into JLU-Liu4 has further influence on the adsorption properties of the solid. As in the case of $\mathbf{3}^{\prime}$, the hysteresis related to the guest induced structural changes is shifted to a lower pressure
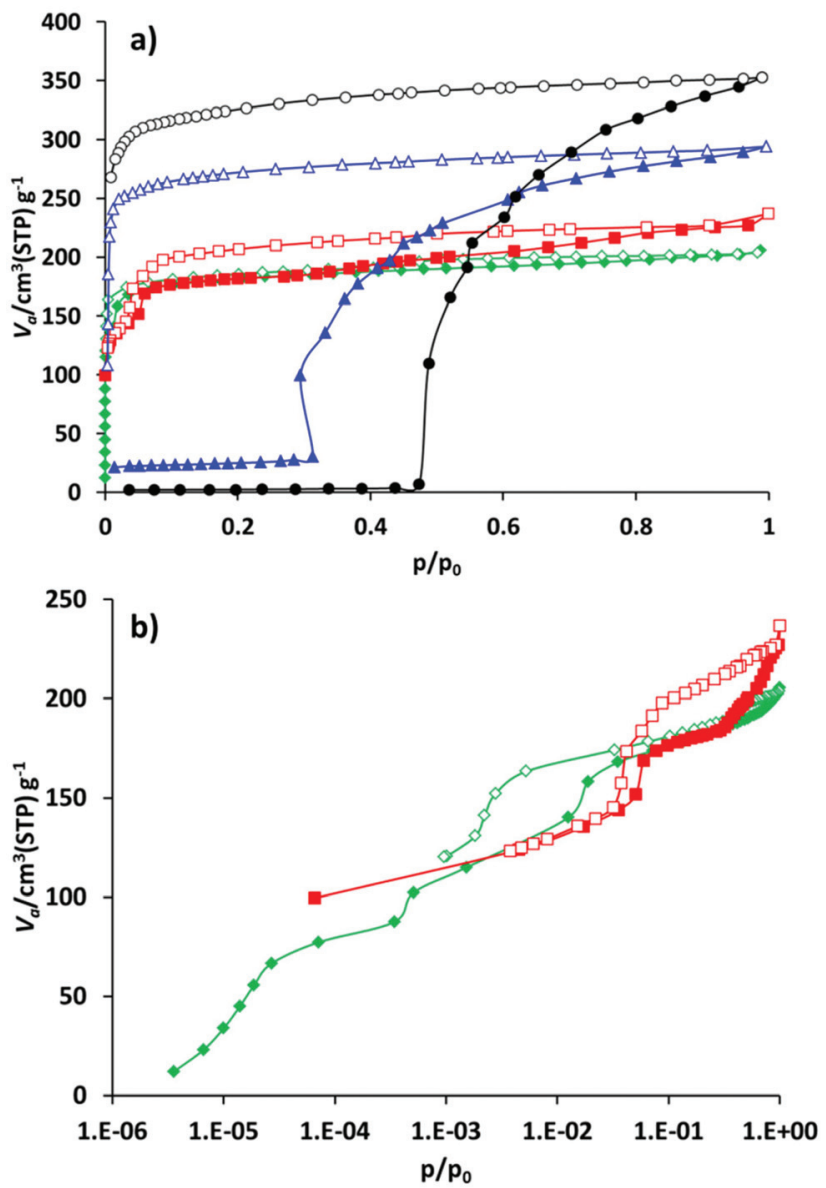

Fig. 5 Nitrogen physisorption isotherms for compounds 1'-4' at $77 \mathrm{~K}$ : (a) linear representation of the isotherms; (b) isotherms of compounds $3^{\prime}$ and 4' on a semilogarithmic scale. Black circles - 1', blue triangles - 2', red squares $-3^{\prime}$, and green diamonds $-4^{\prime}$. Close symbols - adsorption, and open symbols - desorption.

range, and is located between $p / p_{0}=5 \times 10^{-3}$ and $p / p_{0}=$ $5 \times 10^{-2}$. The isotherm reaches saturation at $p / p_{0}=0.95$ showing the nitrogen uptake of $203 \mathrm{~cm}^{3} \mathrm{~g}^{-1}$.

While the structural transformations during the adsorption of nitrogen on $\mathbf{1}^{\prime}$ and $\mathbf{2}^{\prime}$ are supposed to be one step "gate opening" (Scheme 2), the adsorption behaviour of $\mathbf{3}^{\prime}$ and $\mathbf{4}^{\prime}$ was studied by parallelized adsorption and PXRD experiments. The PXRD patterns recorded on the evacuated material $3^{\prime}$ and at the first adsorption point (Fig. 6, PXRD no. 1) show the presence of a narrow pore phase. Surprisingly, further five PXRD patterns, recorded in the relative pressure range from $5 \times 10^{-4}$ up to $10^{-1}$, show a shift of the main (101) reflection from $2 \theta=7.19^{\circ}$ to $7.44^{\circ}$, indicating the formation of an intermediate phase (ip) and contraction of the unit cell (Fig. 4, PXRD patterns no. 2-6). Unfortunately, the patterns could not be indexed unambiguously because of the presence of the reflections of more than one phase. Further increase of the gas pressure leads to the gradual shift of the (101) reflection back to lower angles, but the initial position is not completely reached (Fig. 4, PXRDs no. 2 and 7). The PXRD patterns, obtained in 

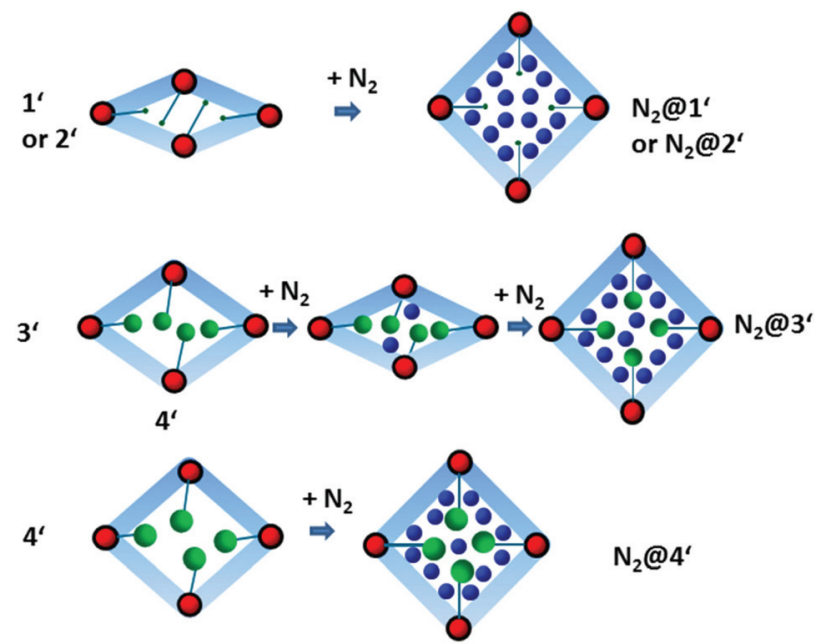

Scheme 2 Mechanisms of structural transformation during the adsorption of $\mathrm{N}_{2}$ at $77 \mathrm{~K}$ for 1-4.

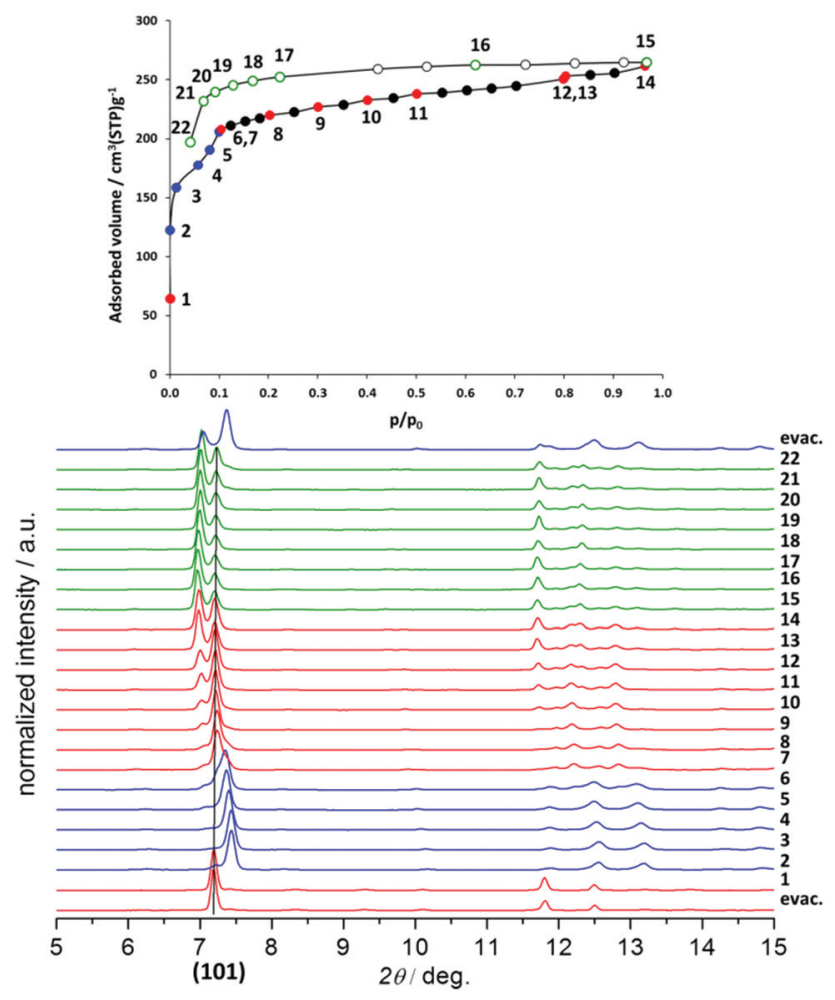

Fig. 6 Adsorption of $\mathrm{N}_{2}$ at $77 \mathrm{~K}$ on $3^{\prime}$ monitored in situ by PXRD.

the $p / p_{0}$ range of 0.1 to 1 are characterized by the intensity increase of the reflection at $2 \theta=6.98^{\circ}$ characteristic for the as made phase 3. Although the PXRD patterns from 2 to 6 could not be indexed, the shape of the isotherm as well as the reflection shift suggest that the transition is similar to the breathing phenomena, observed in MIL-53(Cr) and MIL-53(Al) materials. ${ }^{26}$ Desorption of nitrogen proceeds without phase transitions showing the presence of a mixture of compounds

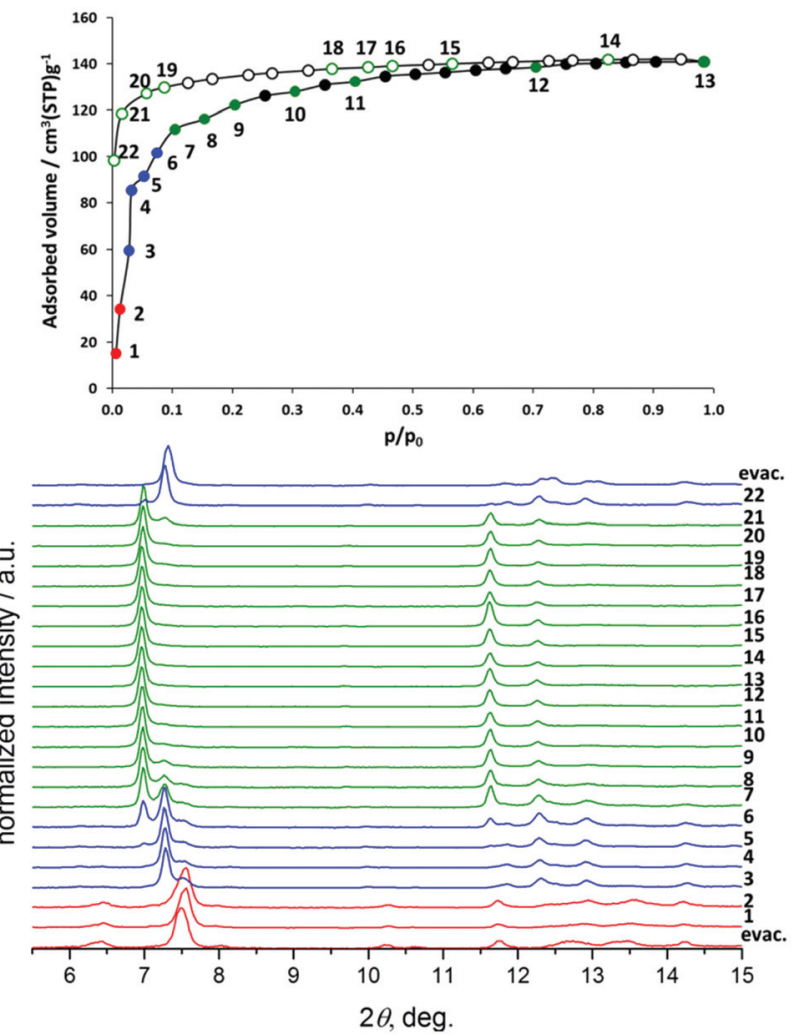

Fig. 7 Adsorption of $\mathrm{N}_{2}$ at $77 \mathrm{~K}$ on 4' monitored in situ by PXRD.

$3^{\prime}$ and 3 up to low pressures. Only evacuation of the sample after the experiment at room temperature leads to structural transformation to the initial narrow pore state.

Nitrogen physisorption at $77 \mathrm{~K}$ combined with PXRD analysis of $\mathbf{4}^{\prime}$ (Fig. 7) reveals a completely different structural transformation induced by the cinnamate anion (Scheme 2). The PXRD pattern of completely evacuated $4^{\prime}$ shows a reflection at $2 \theta=7.50^{\circ}$ matching the intermediate phase, obtained during the adsorption of nitrogen on $3^{\prime}$. Indeed, the direct comparison of the above mentioned PXRD patterns shows good match (Fig. S11, ESI $\dagger$ ). The indexing of the PXRD patterns obtained from evacuated $4^{\prime}$ gives several possible unit cells, one of which is an orthorhombic C-centered unit cell. Taking into account that $\mathbf{1}^{\prime}$ crystallizes in the same crystal system, this unit cell was used for the Rietveld refinement. The pore volume calculated from the final structural model matches with the value estimated from the adsorption isotherm of the compound.

Although the adsorption isotherms of $\mathbf{3}^{\prime}$ and $\mathbf{4}^{\prime}$ are similar to some extent, in situ adsorption/PXRD experiments suggest a distinct pathway for the structural evolution in $4^{\prime}$. In the case of $\mathbf{4}^{\prime}$, the most intense reflection shifts towards lower $2 \theta$ angles with increasing pressure, probably indicating the stepwise opening of the crystal structure. The phase $\mathbf{4}^{\prime}$ exists up to the relative pressure of 0.013 . Further adsorption of nitrogen leads to phase transition, accompanied by the shift of the most intense reflection from $7.50^{\circ}$ to $7.29^{\circ} 2 \theta$. Unfortunately, the pure intermediate phase could not be obtained and 
therefore the PXRD patterns could not be indexed unambiguously. In the relative pressure range between 0.2 and 1 during the adsorption and desorption almost pure phase $\mathbf{4}$ is presented. Only at relative pressures lower than $10^{-2}$, the reversible transformation from $\mathbf{4}$ to the intermediate phase is observed.

\section{Conclusions}

In summary, the fine tuning of the gate pressure and switchability in JLU-Liu- 4 was possible by modification of the SBU. Compounds containing coordinated formate, acetate, benzoate or cinnamate anions on the cluster have the same frameworks with the ant topology, but show variations in structural transformation during the adsorption of nitrogen at $77 \mathrm{~K}$. While the utilisation of small carboxylic acids during the synthesis (compounds 1 and 2) results in complete closing of the framework after solvent removal and therefore "gate opening" behaviour during the adsorption, bulkier carboxylates lead to incomplete closing of the frameworks after desolvation. Compounds containing benzoate $\left(\mathbf{3}^{\prime}\right)$ and cinnamate $\left(\mathbf{4}^{\prime}\right)$ anions show nearly the same adsorption behaviour but undergo completely different structural transformation during the adsorption. While the structural changes during adsorption on $3^{\prime}$ could be rather described as classical breathing, ${ }^{27}$ the changes in $\mathbf{4}^{\prime}$ lead to the step-wise increase of the unit cell volume. We believe that this approach can be further generalized and applied for other flexible MOFs with coordination vacancies on the metal cluster (typically $\mathrm{Zn}_{3}$ and $\mathrm{Co}_{3}$ clusters) in order to obtain materials with targeted adsorption properties.

\section{Acknowledgements}

N. K. thanks the "excellence initiative by the German federal and state government" (Institutional strategy, measure "support the best"). V. B. thanks the German Federal Ministry for education and research (Project BMBF No. 05K13OD3). The HZB is gratefully acknowledged for the allocation of the synchrotron radiation beamtime on KMC-2 and MX BL14.2 beamlines and for travel grants.

\section{References}

1 A. Schneemann, V. Bon, I. Schwedler, I. Senkovska, S. Kaskel and R. A. Fischer, Chem. Soc. Rev., 2014, 43, 6062-6096.

2 S. Horike, S. Shimomura and S. Kitagawa, Nat. Chem., 2009, 1, 695-704.

3 F.-X. Coudert, Chem. Mater., 2015, 27, 1905-1916.

4 P. Serra-Crespo, M. A. van der Veen, E. Gobechiya, K. Houthoofd, Y. Filinchuk, C. E. A. Kirschhock, J. A. Martens, B. F. Sels, D. E. De Vos, F. Kapteijn and J. Gascon, J. Am. Chem. Soc., 2012, 134, 8314-8317.

5 A. Douvali, A. C. Tsipis, S. V. Eliseeva, S. Petoud, G. S. Papaefstathiou, C. D. Malliakas, I. Papadas,
G. S. Armatas, I. Margiolaki, M. G. Kanatzidis, T. Lazarides and M. J. Manos, Angew. Chem., Int. Ed., 2015, 54, 16511656.

6 H. Sato, W. Kosaka, R. Matsuda, A. Hori, Y. Hijikata, R. V. Belosludov, S. Sakaki, M. Takata and S. Kitagawa, Science, 2014, 343, 167-170.

7 W. Kosaka, K. Yamagishi, A. Hori, H. Sato, R. Matsuda, S. Kitagawa, M. Takata and H. Miyasaka, J. Am. Chem. Soc., 2013, 135, 18469-18480.

8 Z. Chang, D.-H. Yang, J. Xu, T.-L. Hu and X.-H. Bu, Adv. Mater., 2015, 27, 5432-5441.

9 S. Henke, A. Schneemann, A. Wütscher and R. A. Fischer, J. Am. Chem. Soc., 2012, 134, 9464-9474.

10 P. Horcajada, F. Salles, S. Wuttke, T. Devic, D. Heurtaux, G. Maurin, A. Vimont, M. Daturi, O. David, E. Magnier, N. Stock, Y. Filinchuk, D. Popov, C. Riekel, G. Férey and C. Serre, J. Am. Chem. Soc., 2011, 133, 17839-17847.

11 O. Kozachuk, M. Meilikhov, K. Yusenko, A. Schneemann, B. Jee, A. V. Kuttatheyil, M. Bertmer, C. Sternemann, A. Pöppl and R. A. Fischer, Eur. J. Inorg. Chem., 2013, 2013, 4546-4557.

12 Y. Sakata, S. Furukawa, M. Kondo, K. Hirai, N. Horike, Y. Takashima, H. Uehara, N. Louvain, M. Meilikhov, T. Tsuruoka, S. Isoda, W. Kosaka, O. Sakata and S. Kitagawa, Science, 2013, 339, 193-196.

13 J. Wang, J. Luo, J. Zhao, D.-S. Li, G. Li, Q. Huo and Y. Liu, Cryst. Growth Des., 2014, 14, 2375-2380.

14 P. Deria, Y. G. Chung, R. Q. Snurr, J. T. Hupp and O. K. Farha, Chem. Sci., 2015, 6, 5172-5176.

15 I. Gamba, I. Salvadó, G. Rama, M. Bertazzon, M. I. Sánchez, V. M. Sánchez-Pedregal, J. Martínez-Costas, R. F. Brissos, P. Gamez, J. L. Mascareñas, M. Vázquez López and M. E. Vázquez, Chem. - Eur. J., 2013, 19, 1336913375.

16 U. Mueller, N. Darowski, M. R. Fuchs, R. Forster, M. Hellmig, K. S. Paithankar, S. Puhringer, M. Steffien, G. Zocher and M. S. Weiss, J. Synchrotron Radiat., 2012, 19, 442-449.

17 M. D. Winn, C. C. Ballard, K. D. Cowtan, E. J. Dodson, P. Emsley, P. R. Evans, R. M. Keegan, E. B. Krissinel, A. G. W. Leslie, A. McCoy, S. J. McNicholas, G. N. Murshudov, N. S. Pannu, E. A. Potterton, H. R. Powell, R. J. Read, A. Vagin and K. S. Wilson, Acta Crystallogr., Sect. D: Biol. Crystallogr., 2011, 67, 235-242.

18 G. Sheldrick, Acta Crystallogr., Sect. A: Fundam. Crystallogr., 2008, 64, 112-122.

19 A. Spek, Acta Crystallogr., Sect. D: Biol. Crystallogr., 2009, 65, 148-155.

20 Material Studio 5.0, Accelrys Software Inc., San Diego, USA, 2009.

21 V. Bon, I. Senkovska, D. Wallacher, A. Heerwig, N. Klein, I. Zizak, R. Feyerherm, E. Dudzik and S. Kaskel, Microporous Mesoporous Mater., 2014, 188, 190-195.

22 P. A. Heiney, Datasqueeze 2.2.9 Graphical Tool for X-ray Data Analysis, 2012. 
23 C. Serre, S. Bourrelly, A. Vimont, N. A. Ramsahye, G. Maurin, P. L. Llewellyn, M. Daturi, Y. Filinchuk, O. Leynaud, P. Barnes and G. Férey, Adv. Mater., 2007, 19, 2246-2251.

24 V. Bon, N. Klein, I. Senkovska, A. Heerwig, J. Getzschmann, D. Wallacher, I. Zizak, M. Brzhezinskaya, U. Mueller and S. Kaskel, Phys. Chem. Chem. Phys., 2015, 17, 17471-17479.
25 L. Sarkisov and A. Harrison, Mol. Simul., 2011, 37, 12481257.

26 C. Serre, F. Millange, C. Thouvenot, M. Noguès, G. Marsolier, D. Louër and G. Férey, J. Am. Chem. Soc., 2002, 124, 13519-13526.

27 G. Ferey and C. Serre, Chem. Soc. Rev., 2009, 38, 13801399. 